\title{
Prevention of weld-decay in austenitic stainless steel by using surface mechanical attrition treatment
}

\author{
Majid Laleh ${ }^{1 *}$, Farzad Kargar ${ }^{1 *}$ and Alireza Sabour Rouhaghdam²
}

\begin{abstract}
Surface mechanical attrition treatment (SMAT) was applied to the samples of a type AISI 304 stainless steel in order to induce grain refinement as well as formation of twins. Transmission electron microscopy and X-ray diffraction analysis results showed that the average grain size at the surface of the SMATed sample was about $10 \mathrm{~nm}$. The untreated and SMATed samples were then welded using a one-pass gas tungsten arc procedure. The heat-affected zone (HAZ) of the samples was examined by optical microscopy and corrosion tests. Results of the double loop electrochemical potentiokinetic reactivation tests showed that the degree of sensitization in the HAZ for the SMATed sample was very low as compared to that of the untreated one. The pre-SMATed sample was resistant to intergranular corrosion. This is mainly due to the formation of high density of twins which are not prone to carbide precipitation because of their regular and coherent atomic structure and extreme low grain boundary energy as compared with those of other grain boundaries.
\end{abstract}

Keywords: Surface mechanical attrition treatment, Grain refinement, Twins, Welding, Degree of sensitization

\section{Background}

Austenitic stainless steels are widely used in a wide range of applications such as steam generating plants (as piping and superheating tube materials), chemical reactors, and nuclear plants due to their excellent corrosion resistance, good mechanical properties, and good weldability at elevated temperatures. Austenitic stainless steels possess excellent resistance to general corrosion; however, when they are subjected to a treatment like welding in the temperature range between $500^{\circ} \mathrm{C}$ and $800^{\circ} \mathrm{C}$, they suffer from corrosion in forms of intergranular corrosion and intergranular stress corrosion cracking. This is generally attributed to sensitization as a result of chromium depletion which in turn is due to the chromium carbide precipitation in the grain boundaries [1-5]. Sensitization as a serious and momentous problem during welding of stainless steel has not been completely prevented by conventional techniques such as reduction of carbon content (below 0.03 wt.\%), addition of strong

\footnotetext{
*Correspondence: laleh.m.1992@gmail.com; Farzad.Kargar@gmail.com 'Materials Engineering Faculty, Islamic Azad University, Najafabad Branch, Isfahan 8514143131, Iran

Full list of author information is available at the end of the article
}

carbide formers (such as titanium, niobium or zirconium), and solution heat treatment. Although these methods have met with various degrees of success, they have increased the cost of the materials without producing sensitization-free materials [6,7]. Recent investigations have revealed that the degree of sensitization (DOS) of austenitic stainless steels depends strongly on the grain size and nature of the grain boundary. Moreover, studies about the grain boundary design and control have shown that materials characterized by a high frequency of low-energy grain boundaries such as coincidence site lattice boundaries are strongly resistant to intergranular precipitation and corrosion [5-12]. It has also been reported that the DOS is inversely related to the grain size and shows a nearly exponential decrease with increasing grain boundary surface area (decreasing grain size) [5]. Surface mechanical attrition treatment (SMAT) is a new and potentially effective method to produce nanostructured surface layers in bulk materials. Investigations indicate that the grain refinement via SMAT process can cause the formation of twins in the materials with low-stacking fault energy, for example, in 304 stainless steel [13-20]. So, in this paper an attempt 


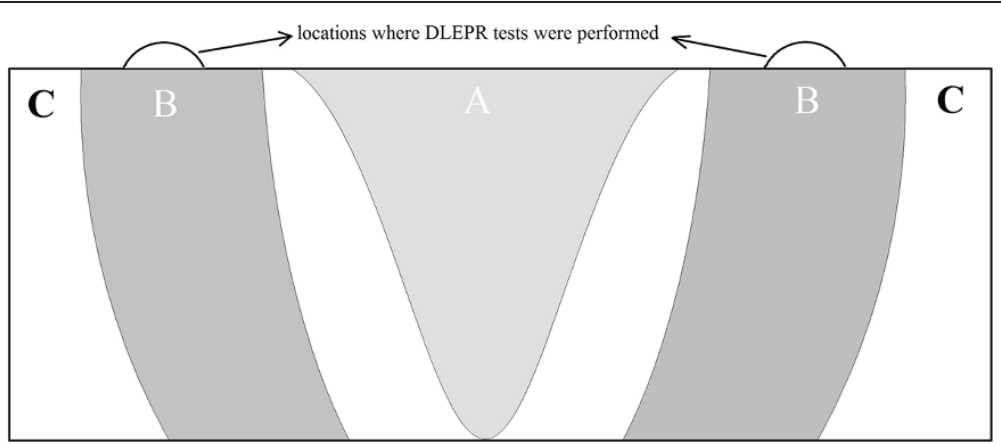

Figure 1 Schematic representation of weld zone. Regions marked with $\mathbf{A}, \mathbf{B}$, and $\mathbf{C}$ are weld metal, HAZ, and base metal, respectively.

was made to evaluate the effect of nano grains and twins formation in the 304 stainless steel (by using SMAT) on the prevention of weld-decay.

\section{Methods}

AISI 304 stainless steel samples with chemical composition of C 0.055, Cr 18.28, Ni 8.48, Mn 1.1, Si 0.60, and balance Fe (wt.\%) were used in this study as initial samples. Before welding and SMAT processes, in order to gain homogeneous coarse-grained structure, the specimens were annealed at $1,070^{\circ} \mathrm{C}$ for $1 \mathrm{~h}$ and then water-quenched. Rectangular samples of dimensions $50 \times 20 \times 8 \mathrm{~mm}^{3}$ were machined from the aged material. In order to induce grain refinement in the surface of the samples, SMAT was performed under vacuum at room temperature for $30 \mathrm{~min}$ with a vibrating frequency of $20 \mathrm{kHz}$ and with spherical stainless steel balls of $3 \mathrm{~mm}$ diameter. Microstructural feature in the surface layer of the SMATed sample was characterized by using a Philips EM-420 transmission electron microscope (TEM) (Philips Electronics, Amsterdam, The Netherlands), operating at a voltage of $120 \mathrm{kV}$. The surface layer structure of the SMATed sample was investigated by X-ray diffraction (XRD) analysis using a Siemens D-500 diffractometer (Siemens AG, Munich, Germany) with $\mathrm{Cu}$ $\mathrm{K} \alpha$ radiation in the range of $40^{\circ}-100^{\circ}$ with a step width of $0.02^{\circ}$. Weldments were prepared by one-pas gas tungsten arc (GTA) procedure without filler and with argon as shield gas in a travel speed of $6 \mathrm{~cm} / \mathrm{min}$. The cross-section of the SMATed sample and heat-affected zone (HAZ) of the welded samples (perpendicular to the welding direction at the surface) were observed with an optical microscope (Olympus BX51M, Shinjuku, Tokyo, Japan). In order to evaluate the intergranular corrosion resistance of the welded samples, double loop electrochemical potentiokinetic reactivation (DLEPR) tests were carried out by a potentiostat/galvanostat (EG\&G Princeton Applied Research 273A, Oak Ridge, TN, USA) system. For electrochemical tests, samples of $8 \mathrm{~mm}$ in thickness were cut perpendicular to the welding direction, as depicted in Figure 1, and then mounted in resin with a copper wire attached in the back side of the sample for connection to the potentiostat. The HAZ of the samples, $10 \mathrm{~mm}$ away from the weld center, was subjected to the DLEPR test to assess the degree of sensitization. Schematic illustration of the weld zone is presented in Figure 1. DLEPR tests were performed in the conventional electrochemical cell with three electrodes: a welded sample as the working electrode, a platinum grid as the counter electrode, and a saturated calomel electrode (SCE) as the reference electrode. During the DLEPR test, the working electrode was immersed in $0.5 \mathrm{M} \mathrm{H}_{2} \mathrm{SO}_{4}+0.01 \mathrm{M} \mathrm{KSCN}$ solution. After the specimens attained a stable open circuit potential (OCP), they were polarized from OCP to $+0.3 \mathrm{~V}$ (vs. SCE) and then reversed at a scan rate of $1.67 \mathrm{mV} . \mathrm{S}^{-1}$ until the OCP. Each test was repeated for three times in order to assure its reproducibility. The ratio of $I_{\mathrm{r}}$ (maximum current density in the reverse scan) and $I_{\mathrm{a}}$ (maximum current density in the anodic scan) was used to evaluate the DOS. Furthermore, a ferric sulfate-sulfuric acid (Streicher) test was also performed to investigate more the resistance of the samples

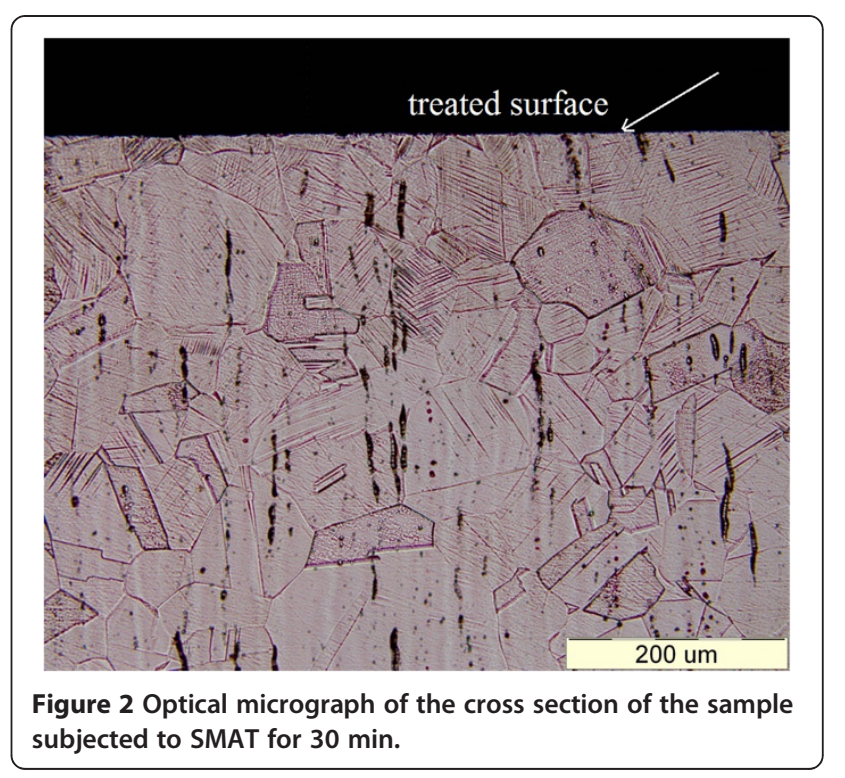




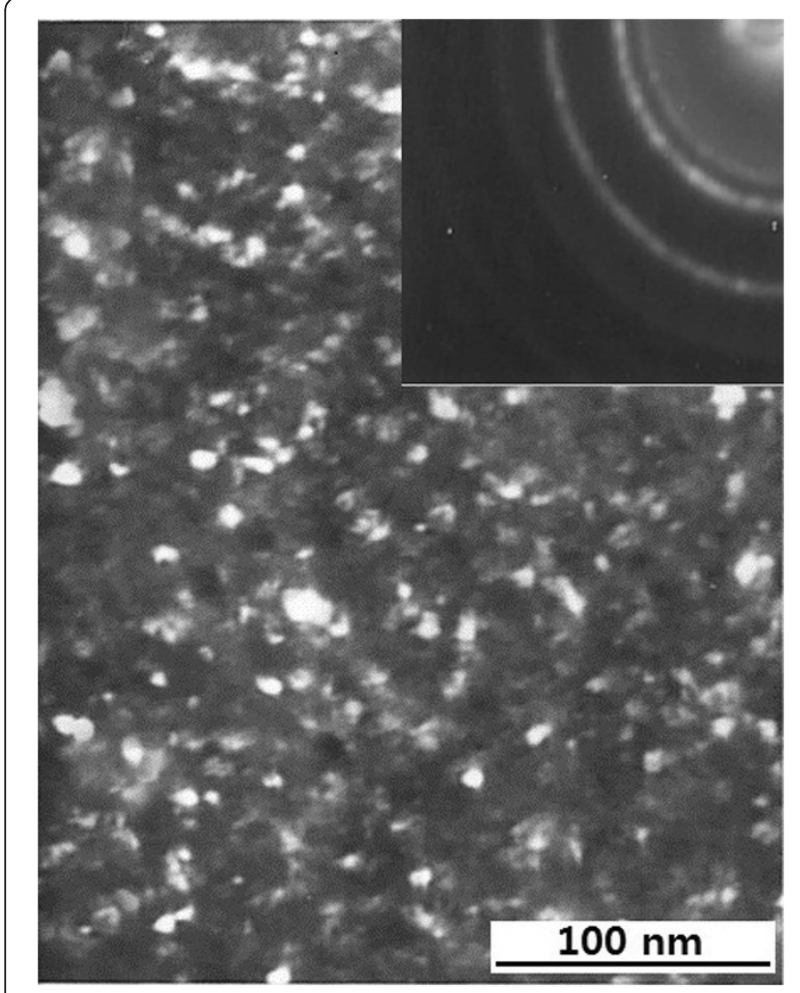

Figure 3 Dark field TEM image of the top treated surface layer for the SMATed stainless steel sample. Inset is the corresponding electron diffraction pattern

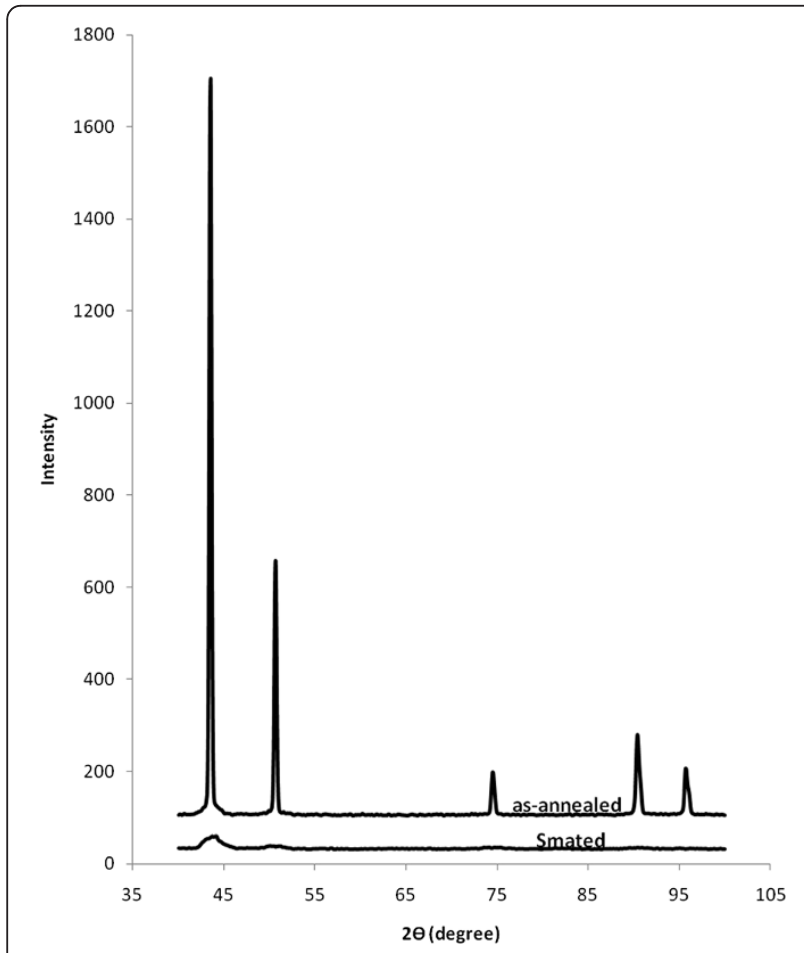

Figure 4 XRD patterns of the as-annealed and pre-SMATed AISI 304 stainless steel samples. to intergranular corrosion. The HAZ of the welded samples after the Streicher test was observed with a scanning electron microscope (SEM, Philips XL-30).

\section{Results and discussion}

Figure 2 shows the cross-sectional optical observation of the SMATed stainless steel. High densities of mechanical twins are identified in the surface layer of the sample. Single twins and the intersections of twins can be clearly seen in the deformed layer with about $300 \mu \mathrm{m}$ thick below the top-treated surface. It is evident that the density of mechanical twins decreases with increasing of the depth from the top surface. Grains cannot be observed in the region about $10 \mu \mathrm{m}$ beneath the top surface with optical microscopy. Figure 3 shows a typical TEM planeview observation of the top surface layer in the SMATed stainless steel sample. It is clear that the microstructure of the top-treated surface layer is characterized by ultrafine equiaxed grains with random crystallographic orientations, as indicated by the dark field image and the

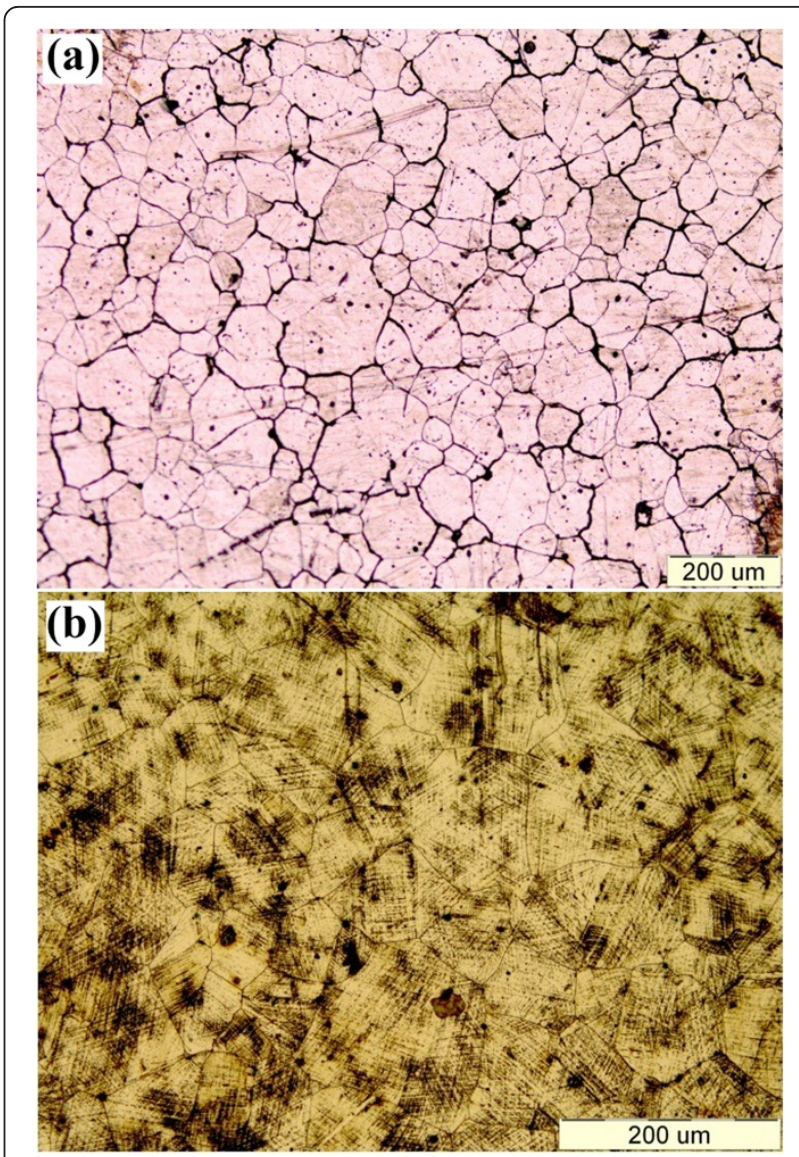

Figure 5 Optical micrographs in the weld HAZs. (a) Untreated and (b) pre-SMATed welded at a travel speed of $6 \mathrm{~cm} / \mathrm{min}$ after electroetching in oxalic acid solution. 


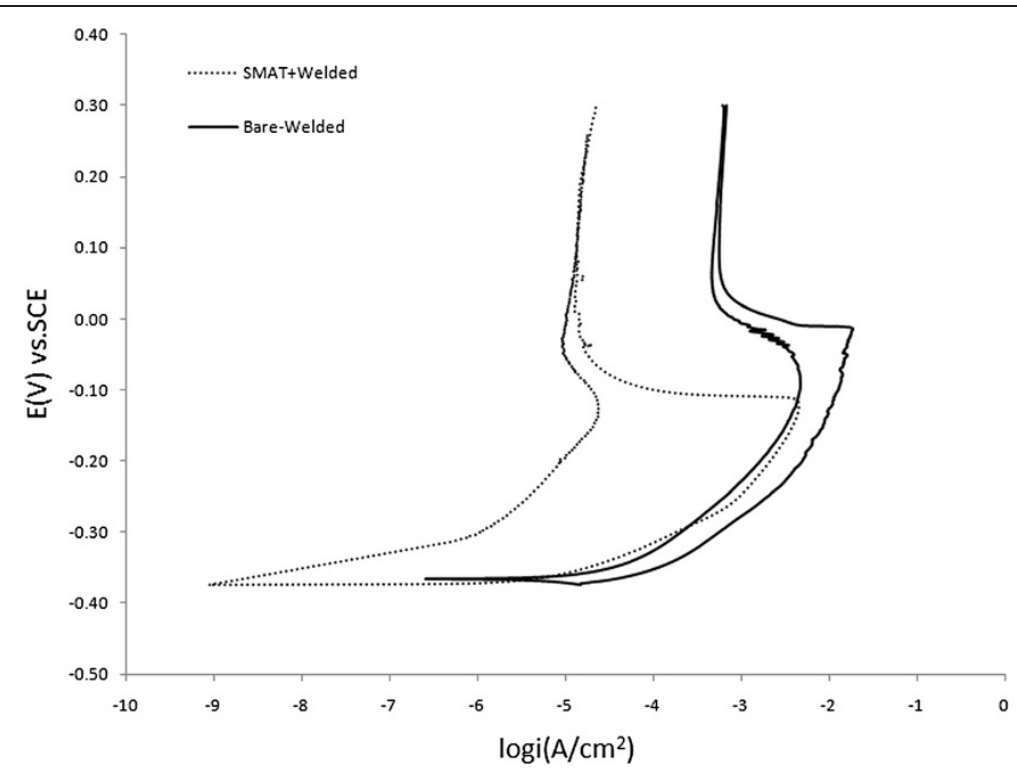

Figure 6 DLEPR curves obtained in the weld HAZs of un-SMATed and SMATed samples.

selected area electron diffraction pattern. As can be seen, the mean grain size in the surface layer is approximately $10 \mathrm{~nm}$. Figure 4 shows the surface XRD patterns of the AISI 304 stainless steel before and after undergoing SMAT for $30 \mathrm{~min}$. It is clear that after the SMAT, the diffraction peaks changed obviously. The full width of half maximum (FWHM) of the diffraction peaks for the SMATed sample is much broader than that of the asreceived sample, which came from the influence of grain refinement. Calculation with Williamson-Hall method (Equation 1) [21] shows that the average grain size in the top surface layer of the SMATed steel is about 10

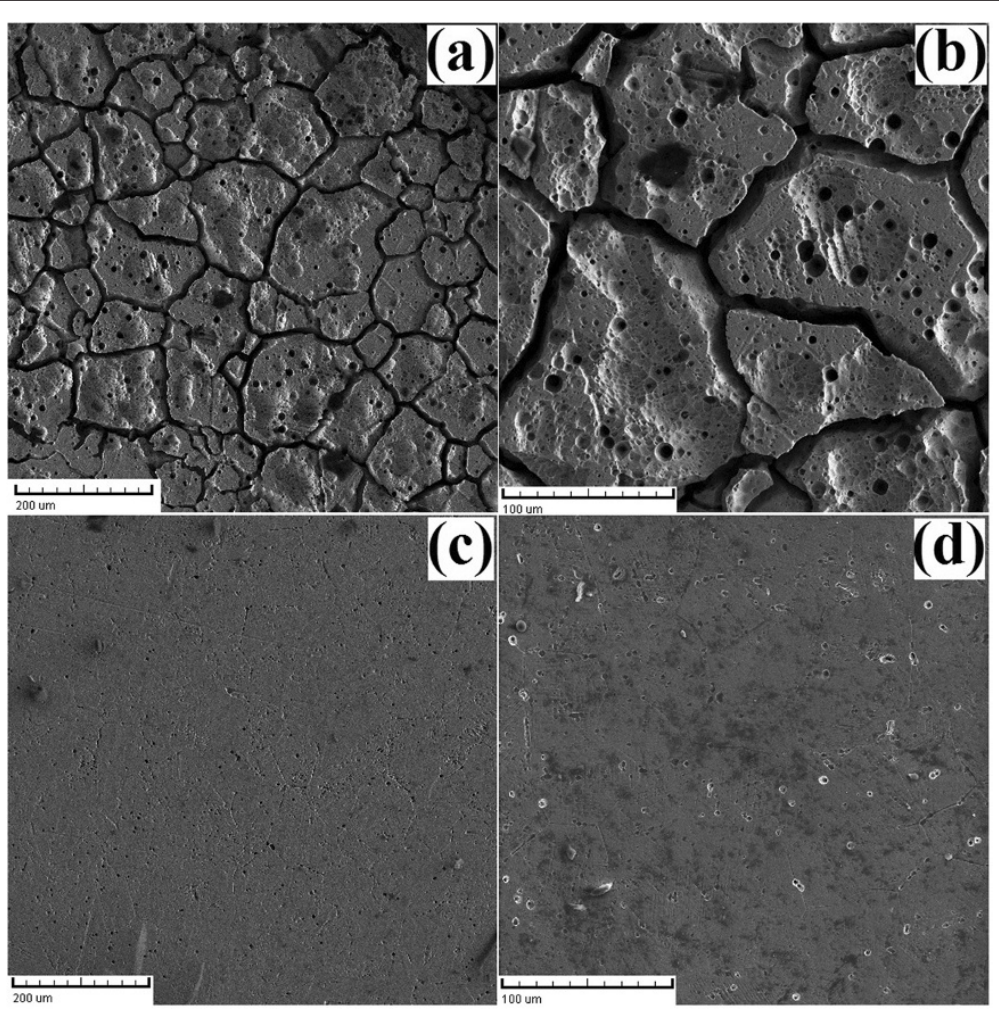

Figure 7 SEM photographs of $(a, b)$ un-SMATed and $(c, d)$ SMATed samples after the Streicher test. 
$\mathrm{nm}$, which is in a good agreement with the results of the TEM observation.

$$
B \cos \theta=\frac{k \lambda}{l}+\eta \sin \theta
$$

Where $B$ is FWHM of the peak $\left(B_{\text {size }}+B_{\text {strain }}\right), \lambda$ is the diffraction angle, $k$ is constant (0.9), $\lambda$ is the wavelength of the X-ray, $l$ is the grain size and $\eta$ is the micro strain. Mechanisms of the grain refinement, formation of nanocrystalline, and twins have been discussed elsewhere by other researchers $[13,14,16]$. The untreated and SMATed samples were then GTA-welded separately at the same conditions. It is well known that the HAZ of the welded metals is more prone to intergranular corrosion $[6,22]$. The HAZ in the surface of the samples perpendicular to the welding direction after electroetching in a $10 \%$ oxalic acid solution is shown in Figure 5. A typical weld-decay region with deep grooving along grain boundaries is clearly observed in the HAZ of the untreated sample as a result of the sensitization (Figure 5a). In contrast, the welded HAZ of the pre-SMATed sample does not show any clear grooved grain boundaries, as shown in Figure 5b. Figure 6 shows representative curves of the DLEPR test for the HAZ region of the as-received and pre-SMATed steel. According to DLEPR tests, DOS $\left(\underline{I}_{\mathrm{r}} / I_{\mathrm{a}}\right.$ ratio $)$ value is about 25 and 0.5 for untreated and pre-SMATed weldments, respectively. Based on Cihal rating about the sensitization of materials [23], the samples can be classified into four sensitivity groups: unsensitized samples (for DOS $<2 \%$ ), samples which are traces of sensitization (for DOS values between $2 \%$ and $8 \%$ ), samples which are considered weakly and medium-sensitized (for DOS values between $8 \%$ and $30 \%$ ), and samples which are severely sensitized (for DOS $>30 \%$ ). So, according to the results of the DLEPR tests (Figure 5), the HAZ of the pre-SMATed sample can be considered as nonsensitized material. Thus, pretreatment with SMAT can suppress the sensitization by a factor of fifty. In order to get more information about the sensitization behavior, the Streicher test was performed for both (untreated and pre-SMATed) welded samples and its results are shown in Figure 7. The weld-decay zone in the HAZ of the untreated sample suffer from severe grain boundary dropping due to deep intergranular corrosion, as shown in Figure 7a,b. However, in the case of the pre-SMATed sample, the HAZ region shows only some shallow grooves along grain boundaries, as depicted in Figure 7c,d. Based on the above results, it can be concluded that the HAZ of the SMATed sample does not show any clear sensitization, unlike what was previously reported for un-SMATed stainless steels $[21,24]$. This fact suggests that the high densities of twins formed in the pre-SMATed sample are not susceptible to intergranular corrosion because of their regular and coherent atomic structure and extreme low grain boundary energy as compared with those of other grain boundaries [7]. On the other hand, SMAT process can cause grain refinement at the surface of metals and decreases grain size significantly. According to Beltran et al. [25], the sensitization is due to the carbide precipitation at the grain boundaries, which requires that the carbides nuclei in the grain boundaries attain a critical size. Furthermore, the growth and size of these carbides determine the extent of $\mathrm{Cr}$ depletion around the grain boundaries and DOS. So, by increasing the subcritical carbide nuclei, the carbon availability in each nucleus is restricted due to sharing with other nuclei. Accordingly, in larger-grained materials which have more $\mathrm{C}$ available per nuclei due to the smaller number of nuclei, the carbide growth is faster. In fact the DOS in larger-grained materials is greater than the finer-grained materials. So, the SMAT can effectively reduce the DOS by two ways: by increasing the grain boundary surface area (decreasing the grain size) and formation of high density of twins.

\section{Conclusions}

Surface mechanical attrition treatment was used as a pretreatment for GTA welding of AISI 304 stainless steel. It was found that SMAT enhanced the degree of sensitization in heat-affected zone as high as $\mathbf{5 0}$ times than the untreated sample. This was mainly due to the formation of high density of twins as well as grain refinement. Twins were not susceptible to intergranular corrosion and sensitization due to their regular and coherent structure and extreme low grain boundary energy as compared with those of other grain boundaries. So the SMAT can effectively prevent the weld-decay of the 304 stainless steel.

\section{Abbreviations}

DLEPR: Double loop electrochemical potentiokinetic reactivation; DOS: Degree of sensitization; FWHM: Full width of half maximum; GTA: Gas tungsten arc; HAZ: Heat affected zone; OCP: Open circuit potential; SCE: Saturated calomel electrode; SEM: Scanning electron microscope; SMAT: Surface mechanical attrition treatment; TEM: Transmission electron microscope; XRD: X-ray diffraction.

\section{Competing interests}

The authors declare that they have no competing interests.

\section{Authors' contributions}

$\mathrm{ML}$ and FK conceived of the study, and participated in its design and coordination. AS revised the final version of the manuscript. All authors read and approved the final manuscript.

\section{Author details}

${ }^{1}$ Materials Engineering Faculty, Islamic Azad University, Najafabad Branch, Isfahan 8514143131, Iran. ${ }^{2}$ Department of Materials Engineering, Faculty of Engineering, Tarbiat Modares University, P O Box 14115-143Tehran 1411713116, Iran.

Received: 10 April 2012 Accepted: 11 October 2012

Published: 28 November 2012 


\section{References}

1. Shaikh, H, Sivaibharasi, N, Sasi, B, Anita, T, Amirthalingam, R, Rao, BPC, Jayakumar, T, Khatak, HS, Raj, B: Use of eddy current testing method in detection and evaluation of sensitisation and intergranular corrosion in austenitic stainless steels. Corros. Sci. 48, 1462-1482 (2006)

2. Jones, R, Randle, V: Sensitisation behaviour of grain boundary engineered austenitic stainless steel. Mater. Sci. Eng. A 527, 4275-4280 (2010)

3. Aydogdu, GH, Aydinol, MK: Determination of susceptibility to intergranular corrosion and electrochemical reactivation behaviour of AISI 316L type stainless steel. Corros. Sci. 48, 3565-3583 (2006)

4. Wasnik, DN, Kain, V, Samajdar, I, Verlinden, B, De, PK: Resistance to sensitization and intergranular corrosion through extreme randomization of grain boundaries. Acta Mater. 50, 4587-4601 (2002)

5. Singh, R, Ghowdhury, SG, Ravi Kumar, B, Das, SK, De, PK, Chattoraj, I: The importance of grain size relative to grain boundary character on the sensitization of metastable austenitic stainless steel. Scripta Mater. 57, 185-188 (2007)

6. Kokawa, H, Shimada, M, Michiuchi, M, Wang, ZJ, Sato, YS: Arrest of welddecay in 304 austenitic stainless steel by twin-induced grain boundary engineering. Acta Mater. 55, 5401-5407 (2007)

7. Shimada, M, Kokawa, H, Wang, ZJ, Sato, YS, Karibe, I: Optimization of grain boundary character distribution for intergranular corrosion resistant 304 stainless steel by twin induced grain boundary engineering. Acta Mater. 50, 2331-2341 (2002)

8. Parvathavarthini, N, Mulki, S, Dayal, RK, Samajdar, I, Mani, KV, Raj, B: Sensitization control in AISI 316L(N) austenitic stainless steel: defining the role of the nature of grain boundary. Corros. Sci. 51, 2144-2150 (2009)

9. Michiuchi, M, Kokawa, H, Wang, ZJ, Sato, YS, Sakai, K: Twin-induced grain boundary engineering for 316 austenitic stainless steel. Acta Mater. 54, 5179-5184 (2006)

10. Trillo, EA, Murr, LE: Effect of carbon content, deformation, and interfacial energetic on carbide precipitation and corrosion sensitization in 304 stainless steel. Acta Mater. 47, 235-245 (1998)

11. Hong, $\mathrm{HU}, \mathrm{Nam}, \mathrm{SW}$ : The occurrence of grain boundary serration and its effect on the $\mathrm{M}_{23} \mathrm{C}_{6}$ carbide characteristics in an AISI 316 stainless steel. Mater. Sci. Eng. A 332, 255-261 (2002)

12. Hong, $\mathrm{HU}, \mathrm{Rho}, \mathrm{BS}, \mathrm{Nam}, \mathrm{SW}$ : Correlation of the M23C6 precipitation morphology with grain boundary characteristics in austenitic stainless steel. Mater. Sci. Eng. A 318, 285-292 (2001)

13. $L u, K, L u, J:$ Nanostructured surface layer on metallic materials induced by surface mechanical attrition treatment. Mater. Sci. Eng. A 375, 38-45 (2004)

14. Zhang, HW, Hei, ZK, Liu, G, Lu, J, Lu, K: Formation of nanostructured surface layer on AISI 304 stainless steel by means of surface mechanical attrition treatment. Acta Mater. 51, 1871-1881 (2003)

15. Ronald, T, Retraint, D, Lu, K, Lu, J: Fatigue life improvement through surface nanostructuring of stainless steel by means of surface mechanical attrition treatment. Scripta Mater. 54, 1949-1954 (2006)

16. Tao, NR, Lu, K: Nanoscale structural refinement via deformation twinning in face-centered cubic metals. Scripta Mater. 60, 1039-1043 (2009)

17. Ronald, T, Retraint, $D, L u, K, L u, J$ : Enhanced mechanical behavior of a nanocrystallised stainless steel and its thermal stability. Mater. Sci. Eng. A 445, 281-288 (2007)

18. Lu, AQ, Zhang, Y, Li, Y, Liu, G, Zang, QH, Liu, CM: Effect of nanocrystalline and twin boundaries on corrosion behavior of 316 stainless steel using SMAT. Acta Metal. Sin. 19, 183-189 (2006)

19. Wei, Y, Liu, B, Hou, L, Xu, B, Liu, G: Characterization and properties of nanocrystalline surface layer in $\mathrm{Mg}$ alloy induced by surface mechanical attrition treatment. J. Alloys Compd. 452, 336-342 (2008)

20. Arif, B, Vianto, S, Mahardika, M, Dewo, PL, Swanto, PT, Salim, UA: Effect of surface mechanical attrition treatment (SMAT) on microhardness, surface roughness and wettability of AISI 316L. Mater. Chem. Phys. 125, 418-426 (2011)

21. Williamson, GK, Hall, W: $X$-ray line broadening from filed aluminium and wolfram. Acta Metall. 1, 22 (1953)

22. Garcia, C, de Tiedra, MP, Blanco, Y, Martin, O, Martin, F: Intergranular corrosion of welded joints of austenitic stainless steels studied by using an electrochemical minicell. Corros. Sci. 50, 2390-2397 (2008)

23. Cihal, V: A potentiokinetic reactivation method for predicting the I.C.C and I. G.S.C.C sensitivity of stainless steel and alloys. Corros. Sci. 20, 737-744 (1980)
24. Garcia, C, Martin, F, de Tiedra, P, Blanco, Y, Lopez, M: Pitting corrosion of welded joints of austenitic stainless steels studied by using an electrochemical minicell. Corros. Sci. 50, 1184-1194 (2008)

25. Beltran, R, Maldonaldo, JG, Murr, LE, Fisher, WW: Effects of strain and grain size on carbide precipitation and corrosion sensitization behavior in 304 stainless steel. Acta Mater. 45, 4351-4360 (1997)

doi:10.1186/2228-5326-2-37

Cite this article as: Laleh et al:: Prevention of weld-decay in austenitic stainless steel by using surface mechanical attrition treatment. International Nano Letters 2012 2:37.

\section{Submit your manuscript to a SpringerOpen ${ }^{\circ}$ journal and benefit from:}

- Convenient online submission

$\checkmark$ Rigorous peer review

- Immediate publication on acceptance

- Open access: articles freely available online

- High visibility within the field

- Retaining the copyright to your article

Submit your next manuscript at $>$ springeropen.com 